\title{
60. Inhibitory Effects of Myrmicacin on the Sodium Channel in the Squid Giant Axon
}

\author{
By Toshifumi Takenaka,*) Hidenori HoRIE, *) Hideaki HoRI,*) \\ Tohru Yoshioka, ${ }^{*}$ ) and Yozo IWANAMI**)
}

(Communicated by Yasuji KatsukI, M. J. A., Oct. 12, 1981)

In 1971, Schildknecht and Koob isolated a compound named myrmicacin from the secretions of South American leaf-cutting ants (Atta Sexdons) and identified it as 3-hydroxydecanoic acid.1) They reported that it inhibited germination of collected seeds and spores in the ant's nest during storage. Iwanami and Iwadare reported that myrmicacin and their analogous compounds, myrmic acids, stopped germination, pollen tube elongation and mitotic division of generative nuclei of several higher plants. ${ }^{2)-4)}$ Iwanami et al. also demonstrated that myrmicacin inhibited mitotic division of sea urchin egg.5) These inhibitory effects of myrmicacin was completely reversible when the agent was removed from the medium. From these results, it might be possible to consider that myrmicacin effects on the cell membrane. In this report, the effect of myrmicacin on the axon membrane was studied with voltage clamp technique. We found that myrmicacin and their analogous compounds suppress the Na-current in the axon membrane.

Experiments were performed at Misaki Marine Biological Station of Tokyo University with giant axons of squid, Doryteuthis bleekeri. These axons were $35 \mathrm{~mm}$ in length and $500-700 \mu \mathrm{m}$ in diameter. The internal electrodes consisted of an $80 \mu \mathrm{m}$ glass capillary for measuring the internal potential and $50 \mu \mathrm{m}$ silver wire for sending currents. The glass capillary was filled with $0.6 \mathrm{M} \mathrm{KCl}$ in contact with a $\mathrm{KCl}$-calomel electrode in the shank of capillary. A $25 \mu \mathrm{m}$ bright platinum wire ran through the capillary to reduce the high frequency impedance. The external electrode was a $0.6 \mathrm{M} \mathrm{KCl}$ agar in contact with calomel electrode for membrane potential recording and $\mathrm{Ag}-\mathrm{AgCl}$ wire for current electrode. For the voltage clamp experiment we followed techniques described by Bezanilla et al. ${ }^{6}$ ) The composition of artificial sea water is $490 \mathrm{mM} \mathrm{NaCl}, 10 \mathrm{mM} \mathrm{KCl}$, $10 \mathrm{mM} \mathrm{CaCl}_{2}, 50 \mathrm{mM} \mathrm{MgCl}_{2}$ buffered with $10 \mathrm{mM}$ Tris-HCl to $\mathrm{pH}$ 8.0.

\footnotetext{
*) Department of Physiology, School of Medicine, Yokohama City University, Minami-ku, Yokohama, Japan.

**) Biological Institute, Yokohama City University, Kanazawa-ku, Yokohama, Japan.
} 


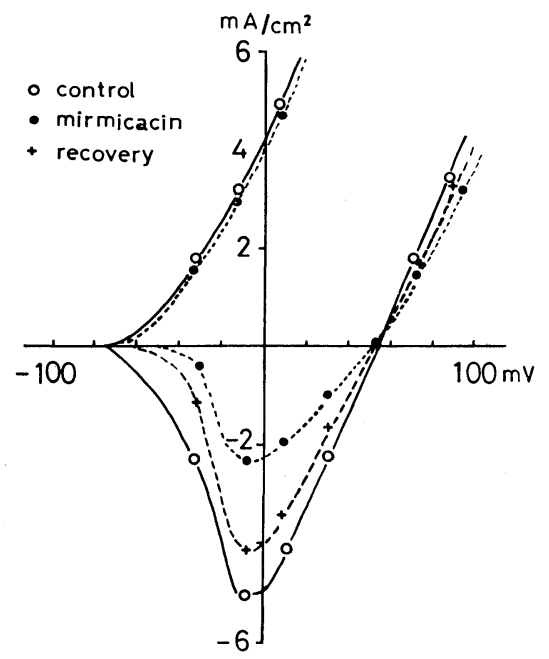

Fig. 1. Current-voltage relation for the peak transient Na-current in an intact squid giant axon before (open circles) and $15 \mathrm{~min}$ after application of $2.1 \mathrm{mM}$ myrmicacin (filled circles) and after washing with artificial sea water (cross symbols).

When myrmicacin was applied externally at the concentration of $0.216-2.16 \mathrm{mM}(10-300 \mathrm{ppm})$ in artificial sea water, it depolarized the nerve membrane $2-5 \mathrm{mV}$ and eventually blocked the action potential. These effects were completely reversible by washing with artificial sea water. The membrane resistance was not changed by this chemical. Fig. 1 represents the current-voltage curve from the axon. The peak of the Na-current was decreased and reached the steady state value 15-20 min after application of myrmicacin. The Nacurrent was suppressed to $50 \%$ of the control at $2.16 \mathrm{mM}, 70 \%$ at $1.44 \mathrm{mM}, 85 \%$ at $0.72 \mathrm{mM}, 90 \%$ at $0.21 \mathrm{mM}$. The time required for Na-current to reach the peak value was measured as a measure of kinetics of the turn-on mechanism of current and there was virtually no effect in this case. Myrmicacin does not affect the late K-current but only the Na-channel. These effects are reversed after washing with normal artificial sea water.

The suppression of the Na-current was studied myrmicacin analogous compounds having different hydrocarbon chains (Table I). Fatty acids less than 8 carbon atoms have no effect on either the Nacurrent or the K-current. The suppression effect was observed when there were 9 and 10 carbon atoms. Fatty acids with more than eleven carbon atoms are almost insoluble in artificial sea water. Next we compared with the effect of fatty acids of the same chain length. Sebacic acid, which has carboxyl groups at both ends of the chain, has no effect on the Na-channel or the resting potential. 10-hydroxy- 
Table I

\begin{tabular}{|c|c|c|}
\hline FATTY ACIDS & $\begin{array}{c}\text { DEPRESSION OF } \\
\text { Na CURRENT }\end{array}$ & $\begin{array}{c}\text { DeCrease of } \\
\text { Resting Potential }\end{array}$ \\
\hline VALERIC ACID & - & - \\
\hline CAPROIC ACID & - & - \\
\hline ENANTHIC ACID & - & - \\
\hline CAPRYLIC ACID & - & - \\
\hline PELARgONIC ACID & + & $3 \mathrm{mV}$ \\
\hline CAPRIC ACID & ++ & $3 \mathrm{mV}$ \\
\hline 2-DECENOIC ACID $\quad(C$ IO) & +++ & $2-3 \mathrm{mV}$ \\
\hline 3 -HYDROXYDECANOIC ACID (C IO) & + & $2-5 \mathrm{mV}$ \\
\hline SEBACIC ACID & - & - \\
\hline I0-HYDROXYDECANOIC ACID (C IO) & - & - \\
\hline
\end{tabular}

Fatty acids and their effects on the Na-current and resting potential. The numbers in parentheses are the number of carbon atoms.

decanoic acid also has no effect on the Na-channel or the resting potential. Myrmicacin decreased the Na-current to about the same extent as pelargonic acid. 2-decenoic acid, which has a double bond between carbon atoms 2 and 3, was most effective fatty acid in our experiments. Th same tendency toward inhibition of the Na-channel was observed when applied these compounds in the intercellularly perfused squid giant axon.

These data show that the suppression of the Na-current depends on the number of carbon atoms in the compounds. However, it is not correct to conclude that the inhibitory activity depends only on number of carbon atoms, because sebacic acid and 10-hydroxydecanoic acid not inhibit the Na-channel. Apparently the inhibitory activity of the compounds is also related to the chemical structure of the compounds. Sebacic acid, having two carboxyl groups at the both extreme ends of carbon chain, is not able to get in the membrane. However, myrmicacin might be able to get into the membrane from the part of lipophilic hydrocarbon chain. Recently, we found that 2-decenoic acid increased the membrane fluidity. ${ }^{7}$ ) From these results it is possible to consider that myrmicacin and their analogous compounds get into the lipid layer of the nerve membrane and increased the membrane fluidity, which caused the perturbation of the membrane lipids and the Na-channel lipoprotein. These changes of the membrane might be the reason to suppress the Na-current of the nerve membrane by application of myrmicacin and their analogous compounds.

The authors are indebted to Dr. T. Iwadare for the generous gift of synthesized myrmicacin. 


\section{References}

1) Schildknecht, H., and Koob, K.: Angew. Chem. Int. Ed., 10, 124-125 (1971).

2) Iwanami, Y., and Iwadare, T.: Bot. Gaz., 139, 42-45 (1978).

3) Iwanami, Y.: Protoplasma, 95, 267-271 (1978).

4) Iwanami, Y., and Iwadare, T.: Bot. Gaz., 140, 1-4 (1978).

5) Iwanami, Y., Tazawa, F., and Iwadare, T.: Cell Struct. Funct., 4, 67-70 (1979).

6) Bezanilla, F., Rojas, E., and Taylor, R. E.: J. Physiol., 211, 729-751 (1970).

7) Kawasaki, Y., Horie, H., and Takenaka, T.: (in preparation). 